\title{
Pre-Test Assessment
}

Thomas Berry, DePaul University

\begin{abstract}
Pre-tests are a non-graded assessment tool used to determine pre-existing subject knowledge. Typically pre-tests are administered prior to a course to determine knowledge baseline, but here they are used to test students prior to topical material coverage throughout the course. While counterintuitive, the pre-tests cover material the student is not expected to know, but serve as a motivational tool and a 'road map' for the students, resulting in improved course performance.
\end{abstract}

Keywords: Pre-tests, assessment, student motivation, quizzing, topic road map, pre-existing subject knowledge

\section{INTRODUCTION}

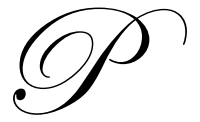

re-tests can be used at beginning of a course to establish a subject knowledge baseline and then related to an end of the course exam to look at knowledge added. Pre-tests can also be used as a way to judge the depth of understanding of prerequisite material. A third purpose, the one explored here, is to test the students just prior to the material being covered in the course. Although counter-intuitive, the pre-tests are covering material that the instructor has not covered and that the student is not expected to know. The idea behind the pre-tests is to give the students an indication of material that will be covered and the depth of knowledge required, thus it serves a 'road map' for the topics. In addition, the instructor gets a quantifiable measure of the knowledge that students already possess for a particular topic.

In this paper we report the results of an experiment using this pre-test methodology in the undergraduate introductory corporate finance course. The course is required of all business majors and is (at least anecdotally) regarded by students as one of the most difficult business school courses. While there are standard prerequisite classes for the finance course it is still a course where the students differ, often widely, in their background knowledge and preparation. Since students differ in terms of their majors, work experience, and backgrounds they have differing levels of understanding of some material. For example, some students, particularly accounting majors, may already know the time value of money while many others will have never seen the topic. Also some students have a fairly thorough understanding of financial markets while others have had very little exposure to the markets. The pre-tests give the instructor an indication of the overall background knowledge on each major topic covered plus the variance of that knowledge, allowing instructors to adjust their presentations accordingly. This has an advantage over simply using class responses to judge background since some students may already have an understanding of certain topics, hence misleading the instructor into thinking the class as a whole has a greater understanding of the material than actually exists.

\section{THE PROCESS}

Students in the introductory financial management course were used to evaluate the pre-tests. The main course material was divided into eight sections (e.g. time value of money, risk and return, capital budgeting, etc.) and a test was devised for each section. The tests varied somewhat depending on the topic but generally contained a handful of multiple choice conceptual questions and some open-ended problems. Angelo and Cross (1993) recommend that the tests contain a few questions that most students should be able to answer correctly and that technical jargon be avoided. A twenty point scale was used for the tests. The tests were given after a very brief (a few minutes) introduction to the topic in that section. Following the pre-test the tests were collected and a lecture on that material began. The corrected pre-tests were returned the next class section. While the pre-test score was not used to evaluate the students' course grades these scores were recorded. The students were then given class time to work on the pre-test questions at various points during the lecture. The students were encouraged (although not 
required) to work in small groups of two or three on the questions and afterwards the instructor would then work through the questions on the board. At the end of a particular topic a graded quiz (i.e. counting toward their course grade) was administered which, while different from the pre-test, was similar in terms of types of problems and material covered. This quiz was also on a twenty point scale.

\section{RESULTS}

The pre-test topics and mean scores are given in Table 1. The total number of students taking the pre-tests for various topics differs due to absences and withdrawals. The pattern of the mean scores is interesting in that it drops after early pre-tests and then rises again with later tests. It is hypothesized that this 'bowl shaped' pattern is due to the greater familiarity of more students to the material covered early in the course such as financial markets and time value of money. The rise in the later pre-test scores is attributed to some students working ahead on material simply to do better on the pre-tests - possibly as a matter of pride. This 'pride' hypothesis was not tested directly but was supported by comments in class evaluations.

The pre-test scores are compared to the graded quizzes that correspond to each topic. These comparisons are also shown in Table 1. The differences in the means are statistically significant for all of the eight topics at a $1 \%$ level. This result is not particularly surprising and it would be disheartening if there were not large differences after covering the material.

Table 1

Pre-Test and Graded Quiz Scores

\begin{tabular}{llllll}
\hline Topic & \multicolumn{2}{l}{ Pre-Tests } & \multicolumn{2}{c}{ Quizzes } \\
& $\underline{\text { Mean }}$ & $\underline{N}$ & $\underline{\text { Mean }}$ & $\underline{N}$ & \\
& & & & 13.43 & 82 \\
1) Financial Markets & 6.08 & 80 & 15.30 & 81 \\
2) Time Value of Money & 8.65 & 78 & 12.94 & 81 \\
3) Risk and Return & 5.79 & 79 & 13.88 & 77 \\
4) Bond and Stock Valuation & 5.38 & 76 & 14.29 & 75 \\
5) Cost of Capital & 5.74 & 76 & 14.96 & 74 \\
6) Capital Budgeting & 6.27 & 72 & 15.39 & 73 \\
7) Capital Structure & 7.44 & 69 & 16.20 & 72 \\
8) Dividend Policy & 8.13 & 72 & &
\end{tabular}

All differences in means are significant at the $1 \%$ level. The number of students $(\mathrm{N})$ varies due to absences and withdraws.

To actually test whether the pre-tests are helping the students requires a comparison of the graded quiz results to the scores of a control group of students who did not have the pre-test methodology. A separate sample (different sections of the same course taught by the same instructor) is used for this comparison. The students in these control classes had a standard format of lecture and problem sets (similar to the problems in the pre-tests) followed by graded quizzes that were essentially identical (numerical values and ordering were changed) to the graded quizzes in the sections using the pre-tests. Essentially the only difference between the two groups was taking the pre-test. The comparison results are shown in Table 2.

The results show that the students using the pre-test methodology performed better on average with one exception than those using the standard pedagogy, significantly so in six of the eight topics based on t-tests for differences in means. However, it may be that even these comparisons are somewhat biased since the pre-tests may give an edge to those students in terms of giving them a better indication of what the actual graded quizzes may look like or the instructor may inadvertently prep the students with the pre-tests. It is also possible that the advantage for the pre-test students is short-term and may not survive after later topics are covered. Michaels (2002), for example, finds that the use of pre-tests does not predict final grades except at the top and bottom ends of the distribution, although his pre-tests are only used at the beginning of the course, not prior to each topic. 
Table 2

Graded Quiz Scores for Pre-test and Control Groups

\begin{tabular}{lcc}
\hline Topic & Pre-Test Students & Control Group \\
\hline & $\underline{\text { Mean }}$ & $\underline{\text { Mean }}$ \\
1) Financial Markets & 13.43 & $11.86^{*}$ \\
2) Time Value of Money & 15.30 & $13.75^{*}$ \\
3) Risk and Return & 12.94 & 13.02 \\
4) Bond and Stock Valuation & 13.88 & $14.91^{*}$ \\
5) Cost of Capital & 14.29 & $15.33^{*}$ \\
6) Capital Budgeting & 14.96 & $15.87^{*}$ \\
7) Capital Structure & 15.39 & $16.74^{*}$ \\
8) Dividend Policy & 16.20 & 16.91 \\
\hline
\end{tabular}

* Significantly different at the 5\% (or less) level

To see if the pre-test effect is temporary or actual longer term learning the final exam scores of the students using the pre-test methodology were compared to the control group who had the standard format. The final exams were comprehensive and nearly identical for the two groups. The mean score for the pre-test group was 76.76 compared to a mean of 72.74 for the control group (a significant difference at the 5\% level). In addition the correlation between the pre-test scores and the final exam score was $52 \%$ and from the graded quizzes to the final exam the correlation was $81 \%$. It does appear that this pre-test methodology helps students master the material better than a standard methodology.

\section{SOME CONCLUSIONS AND CAVEATS}

While the results are encouraging and show that the pre-tests can improve student performance, there are some concerns to using this pedagogy. It is imperative that the instructor continually reminds the students that the pre-test scores do not count and that any score above zero means they are ahead on the material. As noted by Angelo and Cross (1993) one of the disadvantages of this methodology is the demoralization that is possible due to the low scores - which are inevitable since the material has not been covered. It is also possible that since the pretests are not graded, the students will not take them seriously and just fill them out to get them over with. Hence, it is important to point out that the pre-tests are designed to help them and that taking them seriously will help their actual scores and make studying more efficient.

The most serious concern for this methodology is the time factor. Both the amount of class time used for the pre-tests and the time to grade them are drawbacks. There are a number of ways this problem can be mitigated. First, the pre-tests can be designed so as to minimize grading time, e.g. using multiple-choice questions. Another possibility, one currently being explored by the author, is moving the pre-tests to an on-line format. Most major publishers now offer on-line homework management systems or testing systems that can be used to run the pre-tests without using class time. Motivation to complete the pre-tests can be done by offering some nominal points for completion (regardless of the score). Although these concerns are serious the evidence suggests that the methodology can improve student learning and are worth consideration.

\section{AUTHOR INFORMATION}

Thomas D. Berry, Vincent DePaul Professor, and Associate Professor of Finance has been teaching at DePaul University since 1981. He specializes in the area of corporate financial management and has taught graduate and undergraduate courses in financial theory, corporate case analysis, managerial finance, and decision theory. Additionally he has taught in numerous international venues including Poland, the Czech Republic, Germany, France, Bahrain, and Russia. His teaching has resulted in numerous awards, he has been an active participant in many professional organizations, and he has published numerous articles in professional journals. 


\section{REFERENCES}

1. Angelo, T and K. Cross, Classroom Assessment Techniques, $2^{\text {nd }}$ Edition, 1993

2. Michael, M. Using Pre- and Post-Testing in a Liberal Arts Mathematics Course to Improve Teaching and Learning”, MAA Notes \#49, Assessment Practices in Undergraduate Mathematics, Mathematics Association of America, 2002

3. Norman, D. What Goes On in the Mind of the Learner in Learning, Cognition, and College Teaching, W. McKeachie, ed., Jossey Bass, 1980

\section{NOTES}

